\title{
EDIÇÃO SEMIDIPLOMÁTICA DO CADERNO FARMÁCIA SÃO JOSÉ
}

\author{
Stephanne da Cruz Santiago ${ }^{1}$; Patrício Nunes Barreiros ${ }^{2}$ \\ 1. Bolsista PIBIC/CNPq/AF-UEFS, Graduando em Letras com Inglês, Universidade Estadual de Feira de \\ Santana, e-mail: stephannesantiago@gmail.com \\ 2. Orientador, Departamento de Letras e Artes, Universidade Estadual de Feira de Santana, \\ e-mail: patriciobarreiros@uefs.br
}

PALAVRAS-CHAVE: Eulálio Motta; Manuscritos; Edição.

\section{INTRODUÇÃO}

O projeto Edição das obras inéditas de Eulálio Motta tem por intuito editar os documentos que o escritor baiano preservou em seu acervo pessoal, e dentre estes documentos há cadernos, correspondências, datiloscritos, manuscritos diversos, documentos impressos. Este acervo contém diversos tipos de texto, contando também com alguns projetos de publicação de livros inéditos.

O estudo em questão trata-se da edição dos 148 fólios do caderno Farmácia São José, de Eulálio Motta, escrito durante os anos 1940 e 1944. O caderno Farmácia São José faz parte do acervo pessoal do escritor e corresponde a uma pesquisa de fonte primária de extrema relevância para os estudos filológicos.

\section{METODOLOGIA}

As edições dos manuscritos inéditos são elaboradas a partir do método filológico da Crítica Textual (Spina, 1994; Cambraia, 2005; Borges, 2012) e busca oferecer aos leitores uma confiabilidade na edição dos textos, pois o método aplicado tem como objetivo mostrar o texto em movimento, ou seja, as campanhas de escritura, sem privilegiar apenas o texto final (Biasi, 2010). A relevância da pesquisa se dá pelo resgate da memória literária baiana, expondo textos que estavam ameaçados pelo esquecimento.

A edição é o primeiro passo que o pesquisador precisa realizar para seguir com outros tipos de trabalho com os textos. No caderno Farmácia São José, os manuscritos apresentam rasuras, emendas e borrões, evidenciando sua gênese. Para manter o texto fidedigno ao original, foram utilizados símbolos e operadores da crítica genética adaptados aos critérios de edição das obras de Eulálio Motta (Barreiros, 2012).

Para a edição, foram seguidos os seguintes critérios:

1. Indica-se o fólio;

2. As linhas são numeradas de 5 em 5 à margem esquerda;

3. Os textos são transcritos em fonte Times New Roman padrão Word; de tamanho 11, justificados à margem esquerda;

4. Transcreve-se o título como se encontra no original;

5. A rubrica do autor indica-se entre colchetes;

6. São mantidos as interpolações, os lapsos do autor, a ortografia, a acentuação, o uso de maiúsculas, a pontuação e registraram-se todas as correções, emendas, rasuras e acréscimos, através da utilização de símbolos. 
7. A edição corresponde a uma transcrição linearizada acomodando as rasuras, substituições, correções e acréscimos na sequência lógica do texto (não obedecendo a topografia do original);

8. Serão utilizadas notas de pé de página para indicar informações complementares tais como: alternância da cor da tinta, rasgões, furos, manchas, colagens, etc.

\section{RESULTADOS E DISCUSSÃO}

O caderno Farmácia São José contém textos que foram escritos entre os anos de 1940 e 1944, é composto por 147 fólios (reto e verso), e há duas folhas faltando no caderno (75r e 116r), porém a mancha escrita ocupa apenas 145 fólios, contendo manuscritos diversos como rascunho de cartas e crônicas, poemas, anotações de leituras e do cotidiano.

O caderno foi escrito em sua maioria com tinta preta e a lápis, porém há passagens, geralmente correções, marcações e acréscimo de palavras, que encontramos feitas com lápis de cor azul ou vermelho; além de um endereço escrito na parte superior do fólio $1 \mathrm{v}$ com tinta azul. Mede $166 \mathrm{~mm}$ de largura, $237 \mathrm{~mm}$ de comprimento e $20 \mathrm{~mm}$ de espessura.

Ainda que o trabalho filológico tenha sido realizado com manuscritos contendo diversas rasuras, cancelamentos e borrões, a edição ocorreu de forma fluida, além de contar com um exemplar do caderno impresso, foi possível consultar a versão digitalizada, que por meio da ferramenta zoom possibilitou a visualização de detalhes mais difíceis de ver em forma impressa ou no original.

Foram identificados 137 textos no caderno (gráfico 1), dentre eles 54 cartas; 17 poemas; 45 anotações do cotidiano, financeiras, literárias, pessoais e políticas; 11 crônicas; 1 carta de autoria de terceiros; 1 prefácio de livro; 1 peça; 7 citações, 5 delas são poemas.

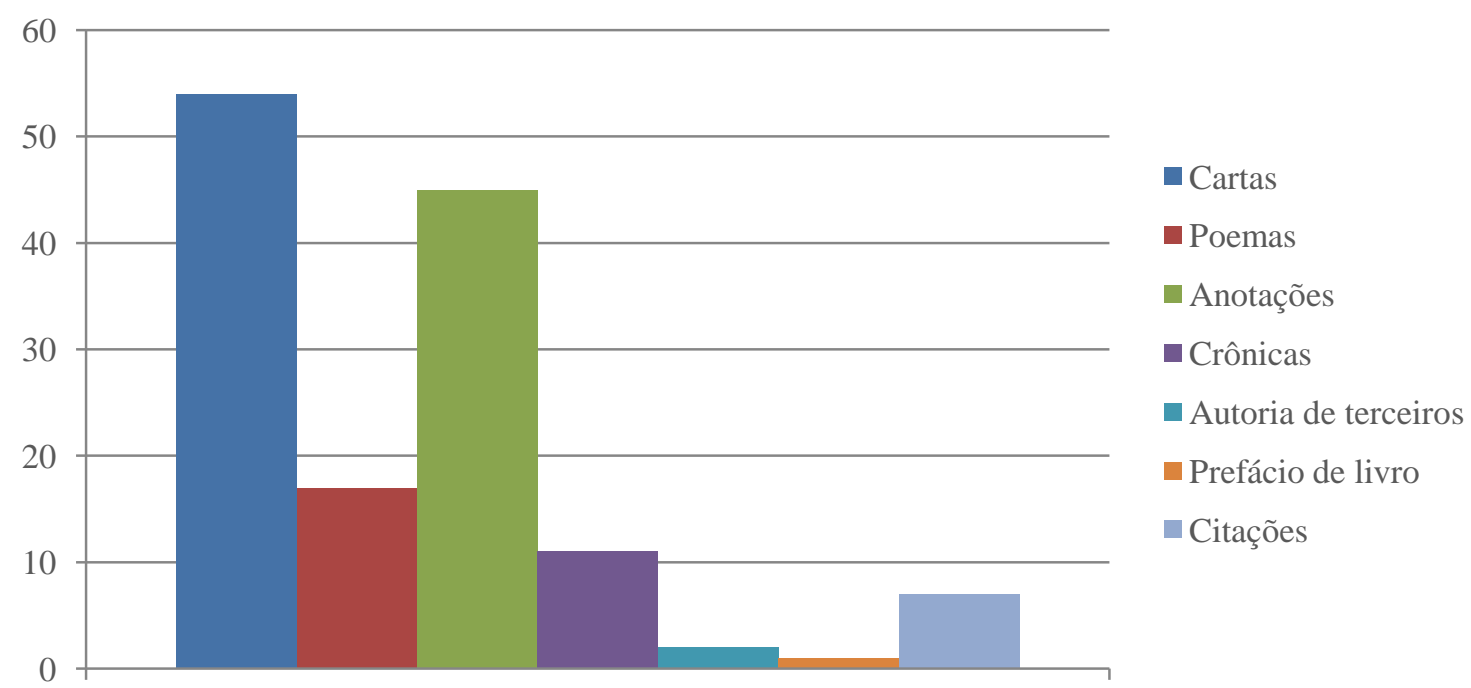

Gráfico 1: Temáticas dos textos editados no caderno Farmácia São José. Cartas - 54; Poemas - 17; Anotações - 45; Crônicas 11; Autoria de terceiros - 2; Prefácio de livro - 1; Citações - 7.

Foram encontradas cinco temáticas nos textos (gráfico 2): religião; amor; pessoal; cotidiano e financeiro; política. 


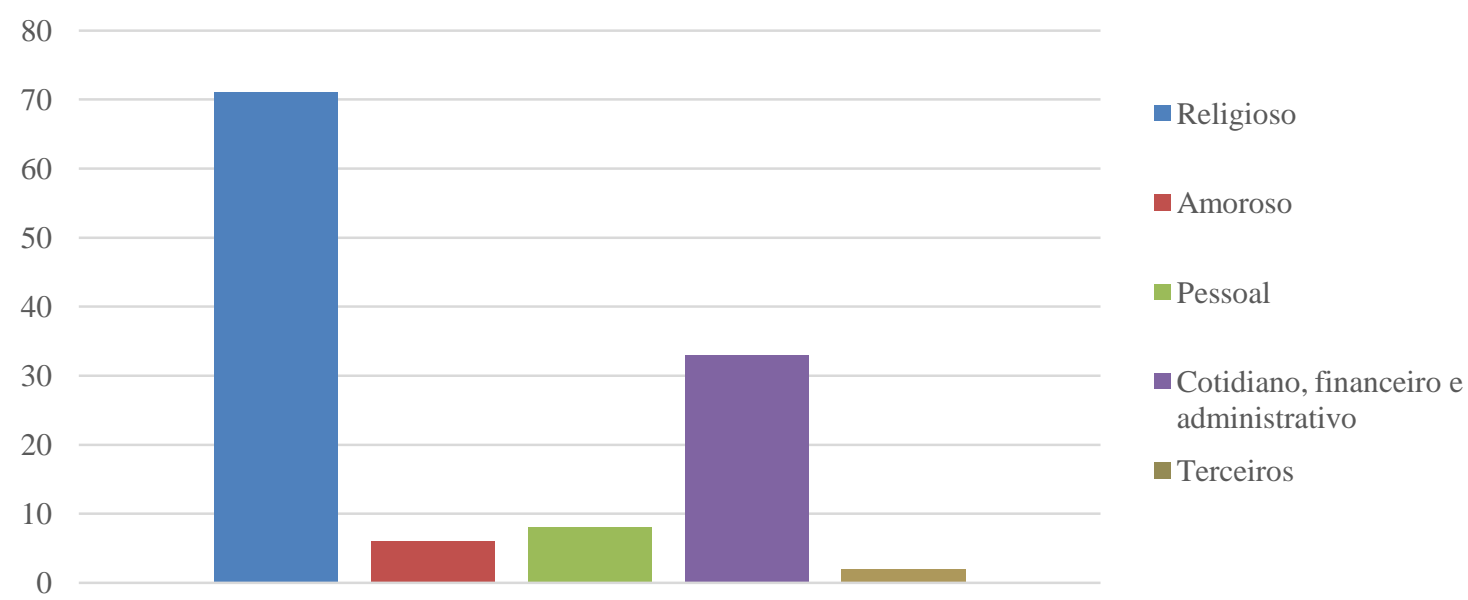

Gráfico 2: Temáticas dos textos editados no caderno Farmácia São José. Religioso - 71 textos; Amoroso - 6 textos; Pessoal - 8 textos; Cotidiano, financeiro e administrativo - 33 textos; Terceiros -2 textos.

Como podemos perceber, a religião é o tema que se destaca no caderno Farmácia São José. A trajetória religiosa de Eulálio Motta foi bastante turbulenta. "Em termo de religião, o Dr. [Eulálio Motta] foi ateu-materialista, converteu-se a religião católica, entrou no espiritismo e há bem pouco andou paquerando as maratas ${ }^{1}$ da Fazenda Havana" (RUBIA, [19-] apud BARREIROS, 2015, p. 61).

Contudo, em $1^{\circ}$ de outubro de 1940 - a mesma data que o autor escreveu na capa do caderno Farmácia São José - Eulálio Motta declarou-se católico, assumindo por vezes uma posição muito crítica em relação a outras religiões, em especial o protestantismo. As críticas religiosas que Eulálio Motta fez por vezes eram diretas e indiretas e estão presentes no caderno Farmácia São José em forma de crônicas, anotações e cartas que foram enviadas para diversos destinatários, entre eles Nemésio Lima, Agenor Brandão, Afonso Carapiá, Eurycles Barreto.

\section{CONSIDERAÇÕES FINAIS}

A presente pesquisa possibilitou a edição de todos os 145 fólios do caderno que contém mancha escrita e, a partir deles, foi possível encontrar dois projetos de publicações inéditas de Eulálio Motta; um das crônicas que compunham sua Ação Católica e outro do livro de poesias Chuva sem sol com uma poesia inédita e homônima ao livro.

É importante salientar que a pesquisa utiliza documentação de acervo e exige muita responsabilidade, além de dedicação e manuseio correto dos manuscritos, é preciso estar atento aos critérios de edição. A partir das edições dos textos, foi possível perceber como se davam as relações do autor com seus amigos e conhecidos; suas ambições em relação ao futuro, seja profissional ou pessoal; seus posicionamentos acerca de temas polêmicos como política e religião e observar a forma como defendia seus ideais.

O plano de trabalho foi cumprido: foram editados todos os fólios do caderno e fez-se a descrição dos mesmos, identificando os textos e as temáticas. O uso da tecnologia foi imprescindível para a realização da edição, visto que alguns textos estavam bastante rasurados e foi necessário utilizar o recurso de ampliação para conseguir identificar os detalhes.

\footnotetext{
${ }^{1}$ Grupo de fanáticos religiosos que se reuniam na Fazenda Havana em Mundo Novo.
} 


\section{REFERÊNCIAS}

BARREIROS, Patrício Nunes. Cantos tristes, no cemitério da ilusão: edição dos sonetos de Eulálio de Miranda Motta. 2007. 346 f. Dissertação (Mestrado em Literatura e Diversidade Cultural) - De- partamento de Letras, Universidade Estadual de Feira de Santana, Feira de Santana.

. O Pasquineiro da Roça, a hiperedição dos panfletos de Eulálio Motta. Feira de Santana: UEFS Editora, 2015.

BIASI, Pierre- Marc. A genética dos textos. Trad. Marie- Hélène Paret Passos. Porto Alegre: EDIPUCRS, 2010.

BORGES, Rosa; SOUZA, Arivaldo Sacramento de. Filologia e edição de texto. In: BORGES, Rosa; SOUZA, Arivaldo Sacramento de; MATOS, Eduardo Silva Dantas de; ALMEIDA, Isabela Santos de. Edição de Texto e Crítica Filológica. Salvador. Quarteto, 2012. p. 15-59.

CAMBRAIA, César Nardelli. Introdução à crítica textual. São Paulo: Martins Fontes, 2005.

RETTENMAIER, Miguel. Pesquisa literária e acervo: a maldição dos manuscritos. Revista do Programa de Pós-Graduação em Letras da Universidade de Passo Fundo, v. 4, n. 2, p. 137 145, jul./dez., 2008.

SPINA, Segismundo. Introdução à edótica: crítica textual. 2. ed. ver. e atual. São Paulo: ArsPoetica/EDUSP, 1994. 